\title{
Inhibitin: A Specific Inhibitor of Sodium/Sodium Exchange in Erythrocytes
}

\author{
Kevin Morgan, Richard C. Brown, Gillian Spurlock, Kay Southgate, and M. Afzal Mir \\ Department of Medicine, Metabolism and Diabetes Unit, and Department of Medical Biochemistry, University of Wales College of \\ Medicine, Heath Park, Cardiff, United Kingdom
}

\begin{abstract}
An inhibitor of ouabain-insensitive sodium/sodium exchange in erythrocytes has been isolated from leukemic promyelocytes. To explore the specific effects of this inhibitor, named inhibitin, sodium transport experiments were carried out in human erythrocytes. Inhibitin reduced ouabain-insensitive bidirectional sodium transport. It did not change net sodium fluxes, had no significant effect on rubidium influx, and did not inhibit sodiumpotassium-ATPase activity. The inhibitory effect of inhibitin was studied on sodium/sodium exchange and on sodium/lithium countertransport in $140 \mathrm{mM}$ sodium and in sodium-free media. In the presence of sodium, inhibitin reduced sodium and lithium efflux to that observed in sodium-free medium. Inhibitin showed no reduction in sodium or lithium efflux when sodium was replaced by choline chloride or $\mathbf{M g}^{2+}$. When inhibitin was combined with one or more of the other transport inhibitors (i.e., ouabain, furosemide, or bumetanide and amiloride), its inhibitable component remained distinct and it did not overlap with that of the other inhibitors. These studies show that inhibitin is a specific inhibitor of carrier-mediated sodium/sodium exchange and sodium/lithium countertransport processes in human erythrocytes.
\end{abstract}

\section{Introduction}

Transport inhibitors have long been used as probes to define and investigate components of sodium and potassium transport in erythrocytes. Digitalis glycosides represent the most extensively studied group of inhibitors and are known to inhibit specifically sodium-potassium-ATPase, which drives active sodium/ potassium countertransport (the sodium pump) $(1,2)$. The glycoside-insensitive, passive transport of sodium has many components which, in the past, have been the subject of much controversy (3-7). In 1966 Hoffman and Kregenow (3) introduced the term "Pump II" which they thought regulated that fraction of passive sodium transport which was inhibitable by ethacrynic acid in the presence of maximal inhibitory concentrations of ouabain. Lubowitz and Whittam (5), supported by Dunn $(6,7)$, argued that "Pump II" was actually carrier-mediated sodium exchange diffusion and did not contribute to net flux.

The chief source of confusion was the lack of a specific inhibitor of sodium/sodium exchange: while Hoffman and Kregenow (3) and later Dunn $(6,7)$ thought that this process was inhibited by diuretics (ethacrynic acid and furosemide), Wiley and Cooper (8) showed that furosemide inhibited an ouabain-

Address reprint requests to Dr. Mir.

Received for publication 21 March 1985 and in revised form 8 October 1985.

J. Clin. Invest.

(C) The American Society for Clinical Investigation, Inc.

0021-9738/86/02/0538/07 \$1.00

Volume 77, February 1986, 538-544 resistant sodium/potassium cotransport process. They concluded that the inhibitory action of furosemide was not explained by inhibition of exchange diffusion. It is now known that the diuretic-sensitive sodium/potassium/chloride cotransport system is distinct from sodium/sodium exchange (9), but more recently Duhm (10) has proposed that the furosemide-sensitive transport system could also operate to achieve sodium/sodium exchange. Various investigators $(11,12)$ have also provided evidence that lithium is carried in the same transport system that mediates sodium/sodium exchange, and that this sodium/lithium countertransport is inhibited by phloretin (11). It is now believed, however, that phloretin is a nonspecific inhibitor of carrier-mediated transport, and produces its effect by interfering with membrane structure (13). In addition, our unpublished studies have shown that the effect of phloretin on sodium transport overlaps with that of other inhibitors (furosemide and ouabain). We have isolated a peptide, named inhibitin, from cultured leukemic promyelocytes which has shown various characteristics consistent with it being a sodium/sodium exchange inhibitor (14). The purpose of this investigation was to explore the mechanism of action of inhibitin and use it in conjunction with other inhibitors to define its effect on sodium transport pathways in the human erythrocyte.

\section{Methods}

\section{Reagents}

All reagents were of Analar grade (BDH Chemicals, Ltd., Poole, Dorset, UK) and prepared in double-glass-distilled water. $\mathrm{Na}^{22}, \mathbf{R b}^{86}$, and ${ }^{3}[\mathrm{H}]$ ouabain were obtained from Amersham International, Ltd. (Amersham, Buckinghamshire, UK).

\section{Isolation and purification of inhibitin}

This method has been described in detail previously (14). Briefly, the supernatant obtained from sonicated cultured leukemic promyelocytes (HL60 cells) was subjected to gel-filtration on Sephadex G-25 Superfine (Pharmacia Fine Chemicals, Hounslow, Middlesex, UK). The peak of active material from this column was then chromatographed on DE-32 ion-exchange resin (Whatman, Maidstone, Kent, UK); the active bound material was eluted and run on a Sephadex G-10 column. Finally the active fraction was subjected to reverse-phase high-performance liquid chromatography (HPLC)' on a Hypersil ODS column (Jones Chromatography, Llanbradach, Mid Glam, UK). Biologically active material eluted in a single sharp peak which was used in the experiments outlined below.

\section{Erythrocyte cation transport}

Blood samples. Fresh human red cells were used in all experiments and drawn on the morning of study by venipuncture into chilled heparinized $(100 \mathrm{U} / \mathrm{ml}$ blood) syringes. As far as possible, blood samples were taken from the same normal healthy volunteers in order to minimize intersubject variation. Typical coefficients of variance for the total, active

1. Abbreviation used in this paper: HPLC, high performance liquid chromatography. 
and passive components of erythrocyte sodium efflux from one subject were 3,5 , and $9 \%$, respectively; these values are based on results obtained from three separate measurements over $6 \mathrm{mo}$

Before use the blood was centrifuged $(5,000 \mathrm{~g})$ and the plasma and buffy coat were removed by aspiration. The cells were washed three times by repeated resuspension and centrifugation in Ringer's solution, which contained (millimolars): $\mathrm{NaCl}, 131 ; \mathrm{KCl}, 8 ; \mathrm{MgSO}_{4}, 1 ; \mathrm{Na}_{2} \mathrm{HPO}_{4}$, 7.2; $\mathrm{NaH}_{2} \mathrm{PO}_{4}, 1.8 ; \mathrm{CaCl}_{2}, 2$; glucose, 10 ; and bovine serum albumin, $0.05 \% \mathrm{wt} / \mathrm{vol} ; \mathrm{pH} 7.4$ with an osmolality of $290 \pm 5 \mathrm{mosmol} / \mathrm{kg}$ water. The external potassium concentration was $8 \mathrm{mM}$ to achieve optimal conditions for active sodium efflux. Leukocytes could be eliminated almost completely by removing the supernatant with the topmost layer of cells after each wash. The final packed cell pellet was used immediately.

Sodium efflux. The methods for determining sodium transport in erythrocytes have been described fully elsewhere (15). For sodium efflux, washed erythrocytes in Ringer's solution (50\% hematocrit) were loaded with $\mathrm{Na}^{22}\left(3 \mu \mathrm{Ci} / \mathrm{ml}\right.$ of erythrocytes) at $37^{\circ} \mathrm{C}$ for $2 \mathrm{~h}$ with periodic agitation. After incubation the cells were separated from the isotopic solution by centrifugation at $4^{\circ} \mathrm{C}$ and washed three times with ice-cold iso-osmotic choline chloride solution which contained (millimolars): choline chloride, $151 ; \mathrm{MgCl}_{2}, 1$; and $\mathrm{CaCl}_{2}, 2.2 ; \mathrm{pH}$ adjusted to 7.4 using Tris. The specific activity of the red blood cells were usually in the region of $0.06 \mu \mathrm{Ci} / \mathrm{ml}$. Loaded red blood cells were added to prewarmed $\left(37^{\circ} \mathrm{C}\right)$ Ringer's solution to give a final packed cell volume of $5 \%$ (i.e., $0.5 \mathrm{ml}$ "loaded" erythrocytes in $10 \mathrm{ml}$ total volume). All experiments were carried out in duplicate or triplicate. Samples were taken at 30,60, and $90 \mathrm{~min}$, and the radioactivity was counted in portions of the suspension and supernatant after centrifugation at $5,000 \mathrm{~g}$. The values of $1-$ (supernatant counts/suspension counts) were plotted semilogarithmically, and the halftime $\left(t_{1 / 2}\right)$ was calculated from the slope of the best-fit line (computer linear regression analysis). The sodium efflux rate constant (i.e., the fraction of intracellular sodium extruded per hour, ${ }^{\circ} \mathrm{K}_{\mathrm{Na}}$ ) was derived from the equation ${ }^{\circ} \mathrm{K}_{\mathrm{Na}}$ $=0.693 / t_{1 / 2}$. The hemoglobin concentration in the supernatant was determined periodically, but the degree of hemolysis was negligible (always $<1 \%$ ) and no corrections were made for fractional hemolysis.

To explore the locus of action of inhibitin on sodium transport pathways across the erythrocyte membrane, sodium efflux experiments were conducted in the presence of inhibitin and various combinations of three other transport inhibitors. Ouabain (Sigma Chemical Co., St. Louis, MO) was used throughout at a final concentration of $0.1 \mathrm{mM}$. Furosemide (a gift from Hoechst Pharmaceuticals, Hounslow, Middlesex, UK) and bumetanide (Leo Laboratories, Ltd., Princes Risborough, Buckinghamshire, UK) were used at final concentrations of 1 and $0.1 \mathrm{mM}$, respectively. Amiloride (a gift from Merck, Sharpe and Dohme, Ltd., Hoddesdon, Hertfordshire, UK) was used at $1 \mathrm{mM}$. Inhibitin was used at $0.1 \mu \mathrm{M}$ final concentration, as the previously published dose-response curve (14) had shown that this concentration reproducibly exhibited $25 \%$ inhibitory activity, except in the sodium/sodium exchange experiments when a final concentration of $1 \mu \mathrm{M}$ was used. The protein concentration of the HPLC peak was determined by quantitative amino acid analysis.

Sodium influx. Sodium influx was measured by a previously described method (15). Erythrocytes $(1 \mathrm{ml})$ were incubated in $20 \mathrm{ml}$ Ringer's solution containing $8 \mu \mathrm{Ci}$ of $\mathrm{Na}^{22}$. After an equilibration period at $37^{\circ} \mathrm{C}$ for $15 \mathrm{~min}$, a 4-ml sample was removed into an ice-cold tube, centrifuged at $4^{\circ} \mathrm{C}$ for $1 \mathrm{~min}$, and washed three times in 5 vol of unlabeled ice-cold iso-osmotic choline chloride solution. Erythrocytes were then hemolyzed in deionized water to a $2-\mathrm{ml}$ volume and the radioactivity was counted. Hemoglobin in the lysate was measured as cyanmethemoglobin at 541 $\mathrm{nm}$ with Drabkin's reagent and the volume of erythrocytes was estimated assuming that $100 \mathrm{ml}$ of cells contain $34 \mathrm{~g}$ hemoglobin. With a known volume of erythrocytes in the two samples, the amount of labeled sodium uptake $(U)$ was calculated from the formula $U=\left(\mathrm{Na}^{75}-\mathrm{Na}^{115}\right) / S A$, where $\mathrm{Na}^{\Omega 5}$ and $\mathrm{Na}^{t 15}$ represented the counts per minute per liter of erythrocytes at 75 and $15 \mathrm{~min}$, respectively, and $S A$ was the radioactive counts per millimole of $\mathrm{Na}^{+}$in the bathing solution. Sodium influx in millimoles per liter per hour $\left({ }^{i} \mathrm{M}_{\mathrm{Na}}\right)$ was estimated from the uptake of radioactivity in $60 \mathrm{~min}$ from ${ }^{\mathrm{i}} \mathrm{M}_{\mathrm{Na}}=U k / 1-\mathrm{e}^{-k t}$, where $U$ was the uptake of labeled sodium in time $t$, and $k$ the $\mathrm{Na}^{+}$efflux rate constant.
The influx rate constant $\left({ }^{i} \mathrm{~K}_{\mathrm{Na}}\right)$ was calculated by dividing ${ }^{i} \mathrm{M}_{\mathrm{Na}}$ by the number of millimoles of $\mathrm{Na}^{+}(140)$ per liter of Ringer's solution. All experiments were performed in the presence of ouabain $(0.1 \mathrm{mM})$ with $0.1 \mu \mathrm{M}$ inhibitin concentration. In the presence of ouabain, sodium influx into red blood cells is linear for up to $4 \mathrm{~h}$ (data not shown).

Net sodium transport. Washed erythrocytes were incubated at $37^{\circ} \mathrm{C}$ in unlabeled Ringer's solution (total volume, $20 \mathrm{ml}$ ) at a hematocrit of $5 \%$ for $5 \mathrm{~h}$. Erythrocyte sodium concentration was determined in the pre- and post-incubation samples and the net sodium transport was calculated by subtracting the preincubation value from the postincubation sodium concentration. To determine internal sodium, erythrocytes were washed three times with ice-cold choline chloride solution (choline chloride, $151 \mathrm{mM} ; \mathrm{MgCl}_{2}, 1 \mathrm{mM}$; and $\mathrm{CaCl}_{2}, 2.2 \mathrm{mM} ; \mathrm{pH}$ 7.4) and the cell suspension was made up to $2 \mathrm{ml}$ after the final wash. The hematocrit was measured in a counter from Coulter Electronics, Inc., Hialeah, FL. $20 \mu \mathrm{l}$ of saponin solution ( $20 \% \mathrm{wt} / \mathrm{vol})$ and $20 \mu \mathrm{l}$ of lithium bromide were added to the sample, and the sodium concentration in the lysate was measured with an intergrating flame photometer (model 227; Evans Electroselenium, Ltd., Halstead, Essex, UK). Standards contained $\mathrm{Na}^{+}$, $\mathrm{K}^{+}$, and $\mathrm{Li}^{+}$at $2.4,36$, and $20 \mathrm{mM} /$ liter, respectively.

Potassium influx. An estimate of potassium influx into ouabaintreated erythrocytes was obtained by following the method of Sachs and Welt (16) except that $\mathbf{R b}^{86}$ replaced $\mathrm{K}^{42}$ because of its longer half-life. Cells were washed three times and added in triplicate, at $5 \%$ hematocrit, to prewarmed $\left(37^{\circ} \mathrm{C}\right)$ Ringer's solution containing $\mathrm{Rb}^{86}(1 \mu \mathrm{Ci} / \mathrm{ml}$ incubating solution). After 30-min equilibration, 4-ml samples were taken into ice-cold tubes. The cells were rapidly separated from the supernatant and washed three times in excess ice-cold choline chloride solution. The erythrocytes were hemolyzed, brought to standard volume with distilled water, and counted in a gamma counter. A second sample was taken 1 $h$ after the first and treated in exactly the same manner. The quantity of cells counted was determined by measuring the hemoglobin, and potassium influx was calculated from the equation: ${ }^{i} \mathbf{M}_{\mathbf{K}^{+}}=\left[\left(\mathbf{R b}^{190}-\mathbf{R b}^{130}\right) /\right.$ $\left.R b_{s}\right]\left(K_{o}\right)$, where ${ }^{i} M_{K}+$ was the influx of potassium in millimoles per liter per hour, $R^{190}$ and $R b^{230}$ were the activities of the cells in counts per minute per liter of cells at 90 and $30 \mathrm{~min}, \mathrm{Rb}_{s}$ was the counts per minute per liter of incubating medium and $\mathrm{K}_{\mathrm{o}}$ the external potassium concentration $(8 \mathrm{mmol} / \mathrm{liter})$.

Lithium/sodium countertransport. The method used for measurement of this process was that of Canessa et al. (17). Erythrocytes were washed three times in $\mathrm{MgCl}_{2}$ solution which contained (millimoles per liter) $\mathrm{MgCl}_{2}, 75$; sucrose, 10; glucose, 10 ; Tris- $\mathrm{HCl}, 10 ; \mathrm{pH}$ 7.4. The cells were then incubated $\left(37^{\circ} \mathrm{C}\right)$ at $20 \%$ hematocrit in $\mathrm{LiCl}$ solution containing (millimolars) $\mathrm{LiCl}, 150$; glucose, 10; Tris- $\mathrm{HCl}, 10 ; \mathrm{pH} 7.4$. After $3 \mathrm{~h}$ the erythrocytes were washed five times in $\mathrm{MgCl}_{2}$ solution at $4^{\circ} \mathrm{C}$. The lithium-loaded cells ( $7 \mathrm{mmol}$ lithium/liter cells) were resuspended at $10 \%$ hematocrit in both $\mathrm{MgCl}_{2}$ solution and in $\mathrm{NaCl}$ solution containing (millimoles per liter) $\mathrm{NaCl}, 145$; glucose, 10 ; Tris- $\mathrm{HCl}, \mathrm{10} ; \mathrm{pH}$ 7.4. Both solutions contained ouabain at a final concentration of $0.1 \mathrm{mM}$. Inhibitin $(0.1 \mu \mathrm{M})$ was added immediately after suspension in these solutions (time zero). After 15 and $75 \mathrm{~min}$, aliquots $(2 \mathrm{ml})$ of the cell suspension were centrifuged at $4,000 \mathrm{~g}$ for $5 \mathrm{~min}$ at $4^{\circ} \mathrm{C}$ and the supernatants were analyzed for lithium. The exact cell volume of each tube was calculated after hemolysis by hemoglobin determination. Ouabain-resistant erythrocyte lithium efflux in both solutions was calculated as the difference between lithium concentration of the supernatant at 75 -min and 15 -min time points, referred to exact packed cell volume; it was expressed as millimoles per hour per liter of erythrocytes. Lithium concentration in the supernatants was measured by flame photometry. Lithium/sodium countertransport was calculated as the difference between lithium efflux in the $\mathrm{NaCl}$ solution and that in the $\mathrm{MgCl}_{2}$ solution.

Sodium/sodium exchange. All these experiments were conducted in the presence of $0.1 \mathrm{mM}$ ouabain and $0.1 \mathrm{mM}$ bumetanide both with and without $1 \mu \mathrm{M}$ inhibitin. Sodium efflux was measured, as described above, in Ringer's solution ( $140 \mathrm{mmol} /$ liter external sodium), choline chloride solution ( $0 \mathrm{mmol} /$ liter external sodium), and Ringer's solution that contained decreasing amounts of sodium $(100,50,30$, and $15 \mathrm{mmol} /$ liter). The composition of other ions in these solutions was the same as 
described for the sodium efflux experiments. Choline chloride was used as a direct substitute for sodium chloride. Sodium/sodium exchange (i.e., external sodium-stimulated sodium efflux) was calculated as the difference in sodium efflux between the $140 \mathrm{mM}$ sodium solution and the choline chloride solution.

Sodium-potassium-ATPase preparation (human erythrocytes). Erythrocyte vesicles were prepared by the method of Charalambous and Mir (18); this method yields high activities of total ATPase and sodium potassium-ATPase with a coefficient of variation of $<8 \%$. Protein concentration was determined by the method of Bradford (19) and ATPase activity by measurement of phosphate release (20).

Ouabain radioreceptor assay. This method is based on that described by Erdmann (21). The plasma and buffy coat were removed from a heparinized blood sample and the erythrocytes were washed three times with Ringer's solution (minus $\mathrm{KCl}$ ), $\mathrm{pH} 7.4$ (composition of other ions as for sodium transport experiments). After the last wash the erythrocytes were diluted to $20 \%$ hematocrit and an aliquot ( $30 \mu \mathrm{l} ; 0.5 \times 10^{9}$ cells) was incubated in Ringer's solution (minus $\mathrm{KCl}$ ), $\mathrm{pH} 7.4$, containing 3 $\mathrm{mM}$ ATP and $2 \mathrm{nM}\left[{ }^{3} \mathrm{H}\right]$ ouabain for $2 \mathrm{~h}$ at $37^{\circ} \mathrm{C}$ (total assay volume 2 $\mathrm{ml})$. Nonspecific $\left[{ }^{3} \mathrm{H}\right]$ ouabain binding was estimated from the amount of radioactivity bound in the presence of $1 \mathrm{mM}$ unlabelled ouabain (usually $10 \%$ of $\left[{ }^{3} \mathrm{H}\right]$ ouabain was nonspecifically bound in this way). At the end of the incubation the erythrocytes were rapidly washed three times in ice cold Ringer's solution (minus $\mathrm{KCl}$ ) by repeated centrifugation $\left(4^{\circ} \mathrm{C}\right)$ and resuspension. The radioactivity of the red blood cell pellet was determined in a scintillation counter (Philips PW 4700; Lab Logic, Sheffield, England); samples were cooled for $2 \mathrm{~h}$ before counting after addition of $6 \mathrm{ml}$ scintillant (Instagel; Packard Instrument Co., Inc., Downers Grove, IL).

Fibroblast sodium transport. Ouabain-insensitive sodium efflux was determined following the procedure of Spurlock et al. (22). Fibroblasts, obtained from skin biopsies of healthy volunteers, were cultured for 4 wk (medium changed twice weekly) in Eagle's minimum essential medium containing $10 \%$ fetal calf serum, $100 \mathrm{U} / \mathrm{ml}$ penicillin, $100 \mu \mathrm{g} / \mathrm{ml}$ streptomycin, $0.225 \%$ sodium bicarbonate, and $2 \mathrm{mM}$ L-glutamine (all reagents were purchased from Flow Laboratories, Inc., Irvine, Scotland) at $37^{\circ} \mathrm{C}$ in an atmosphere of $5 \% \mathrm{CO}_{2}$ in air. The cells were seeded at 5 $\times 10^{4} \mathrm{cells} / \mathrm{ml}$ in 5 -ml-vol petri dishes and were used for transport experiments after $6 \mathrm{~d}$ (two medium changes) when they had reached confluence. The cells were washed twice with $5 \mathrm{ml}$ Hank's balanced salt solution minus potassium that contained (millimolars): $\mathrm{NaCl}, 141 ; \mathrm{CaCl}_{2}$, 1.26; $\mathrm{MgSO}_{4}, 0.4 ; \mathrm{MgCl}_{2}, 0.49 ; \mathrm{Na}_{2} \mathrm{HPO}_{4}, 0.17 ; \mathrm{NaH}_{2} \mathrm{PO}_{4}, 0.44 ;$ $\mathrm{NaHCO}_{3}, 4.17$; and glucose, 5.5, $\mathrm{pH}$ 7.4. The cells were then incubated in $2 \mathrm{ml}$ of Hank's balanced salt solution minus potassium containing 1 $\mu \mathrm{Ci}$ sodium ${ }^{22}$ for $1 \mathrm{~h}$ at $37^{\circ} \mathrm{C}$. At time zero (i.e., after the 60 -min incubation) the radioactive medium was aspirated and the cells were washed with normal Hank's balanced salt solution (composition as above but including $5.4 \mathrm{mM} \mathrm{KCl}$ ) containing $1 \mathrm{mM}$ ouabain before being left in this medium $(5 \mathrm{ml})$ for up to $15 \mathrm{~min}$. At each time point $(0,5,10$, and $15 \mathrm{~min}$ ), quadruplicate dishes were rapidly washed with $3 \times 5 \mathrm{ml}$ choline chloride solution (composition as for erythrocyte washings). Each individual dish of cells was then dispersed in $2 \mathrm{ml} 0.4 \mathrm{M} \mathrm{NaOH}$ and counted for radioactivity and subsequently assayed for protein content. The efflux rate constant was derived from the slope of the plot of log counts per minute versus time in minutes (best-fit line obtained by computer linear regression analysis). The efflux rate (moles sodium per gram protein per minute) was obtained by multiplying the efflux rate constant by the intracellular sodium (usually $0.3 \mu \mathrm{mol}$ sodium $/ \mathrm{mg}$ protein); this was calculated from counts per minute in the cells at time zero divided by the specific activity of the external medium.

Statistical analysis. All results are expressed as mean \pm 1 SD. Cation transport in the presence of inhibitin was compared with that measured in Ringer's solution containing various inhibitors. Unpaired $t$ test was used to determine statistical significance.

\section{Results}

Effect of inhibitin on erythrocyte sodium transport. To confirm our previous finding (14) that inhibitin reduces bidirectional passive sodium transport in erythrocytes we carried out a series of experiments using $0.1 \mu \mathrm{M}$ inhibitin in the presence of 0.1 $\mathrm{mM}$ ouabain. The results are summarized in Table $\mathrm{I} a$ and $b$.

Table I. Effects of $0.1 \mu M$ Inhibitin* in the Presence of Ouabain on (a) Sodium Efflux/Influx, and (b) Net Sodium Transport in Erythrocytes from One Subject

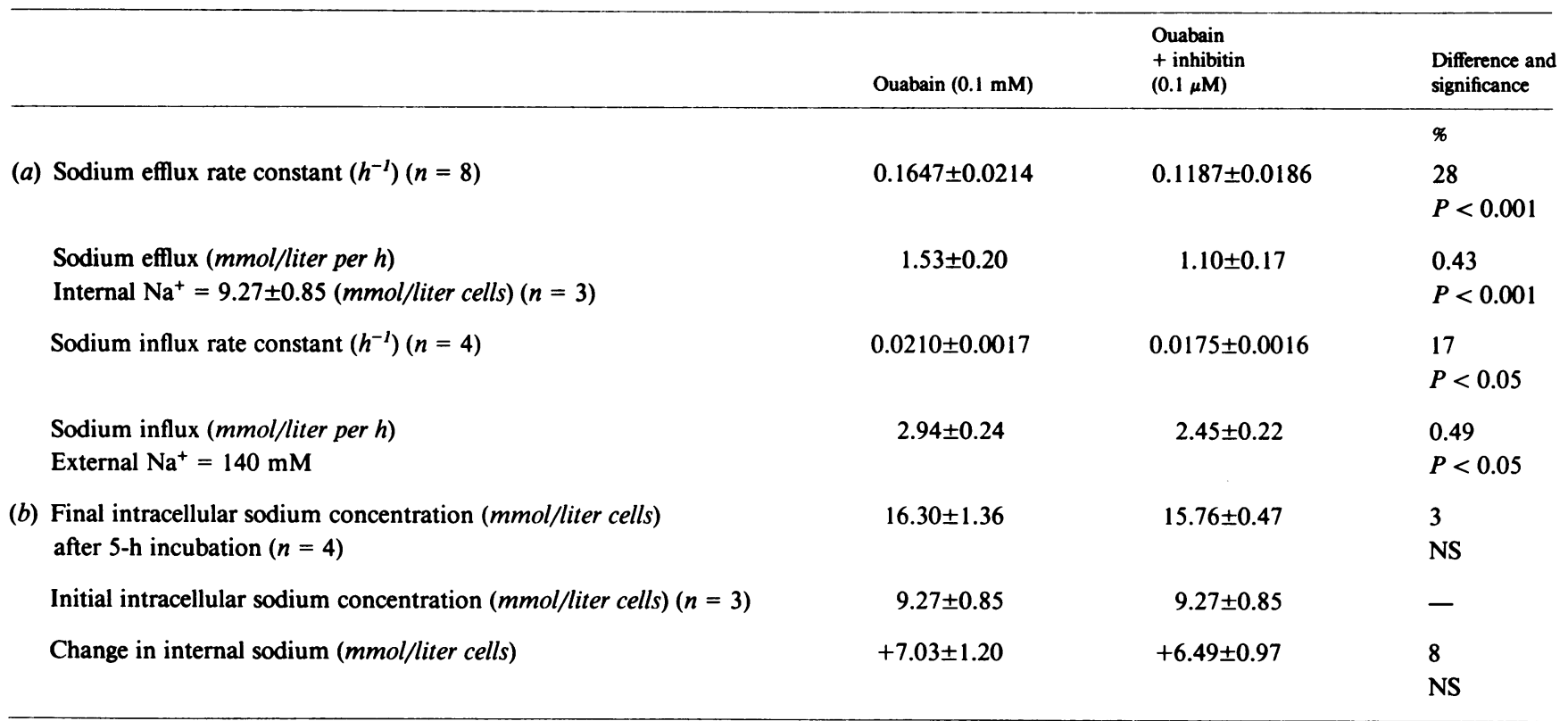

* HPLC material was prepared as described previously (14).

All data are mean $\pm 1 \mathrm{SD}$. The final concentration of inhibitors in the incubation medium is shown in parentheses. Inhibitin decreased both the sodium efflux and influx rate constants, but had no effect on net transport; this indicates its likely locus of action as sodium/sodium exchange. NS, not significant. 
Inhibitin exerted an inhibitory effect in the presence of ouabain, i.e., on ouabain-uninhibitable (passive) movements, decreasing the sodium efflux rate constant from $0.1647 \pm 0.0214$ to $0.1187 \pm 0.0186(n=8, P<0.001)$. Inhibitin also decreased the sodium influx rate constant from $0.0210 \pm 0.0017$ to $0.0175 \pm 0.0016(n=4, P<0.05)$. The inhibitin-sensitive component of sodium efflux amounts to $0.43 \mathrm{mmol} \cdot 1^{-1}$ of erythrocytes $\cdot h^{-1}$, which matches the inhibitin-sensitive portion of sodium influx, $0.49 \mathrm{mmol} \mathrm{l}^{-1} \cdot \mathrm{h}^{-1}$. The mean difference between these fluxes was small $\left(0.06 \mathrm{mmol} \cdot \mathrm{l}^{-1} \cdot \mathrm{h}^{-1}\right)$ and not statistically significant (for these calculations an initial intracellular sodium concentration of $9.27 \mathrm{mmol} / \mathrm{liter}$ cells as measured was used, together with an extracellular concentration of $140 \mathrm{mmol} / \mathrm{liter}$ ). Net sodium fluxes, shown in Table $\mathrm{I} b$, were determined on four paired influx-efflux studies over a 5-h incubation period. Normal human erythrocytes incubated with $0.1 \mathrm{mM}$ ouabain had a final intracellular sodium of $16.30 \pm 1.36 \mathrm{mmol} /$ liter of cells, whereas those incubated with ouabain and $0.1 \mu \mathrm{M}$ inhibitin had an intracellular sodium of $15.76 \pm 0.47 \mathrm{mmol}$ per liter of cells; there being no significant difference between these two values. These data suggest that inhibitin acts on a sodium/sodium exchange mechanism where intracellular sodium is exchanged for extracellular sodium with no net loss or gain.

Effect of inhibitin on erythrocyte potassium movements. Potassium influx experiments in ouabain-treated erythrocytes $(0.1$ $\mathrm{mM}$ ) were conducted as outlined in Methods using $\mathbf{R b}^{86}$ as a potassium tracer. The influx of $\mathrm{Rb}^{86}$ was measured in the presence of furosemide (final concentration, $1 \mathrm{mM}$ ) and inhibitin $(0.1 \mu \mathrm{M})$, both separately and in combination. The external potassium concentration was $8 \mathrm{mM}$. The results of these experiments are outlined in Table II. Inhibitin failed to show a significant reduction of potassium influx. Furosemide produced a highly significant $(P<0.001)$ inhibition in agreement with the observations of Wiley and Cooper (8).

Effect of inhibitin on erythrocyte lithium/sodium countertransport. Since lithium is thought to be transported by the same carrier as sodium/sodium exchange $(11,12)$, we studied the effects of inhibitin on lithium/sodium countertransport by following the method of Canessa et al. (17). In the sodium medium (145 mM), lithium/sodium countertransport is maximal with other processes for passive lithium efflux also occurring, whereas

Table II. Effect of Inhibitin on Potassium Influx (as Measured $B{ }^{86} \mathrm{Rb}$ Uptake) into Ouabain-treated Erythrocytes from Two Donors in the Presence and Absence of Furosemide

\begin{tabular}{lll}
\hline & Potassium influx & $\begin{array}{l}\text { Percent change and } \\
\text { significance }\end{array}$ \\
\hline & $\begin{array}{l}\text { mmol/liter per } h \\
\text { Ouabain }(0.1 \mathrm{mM})(n=12)\end{array}$ & $\%$ \\
$\begin{array}{l}\text { Ouabain }(0.1 \mathrm{mM})+\text { inhibitin } \\
(0.1 \mu \mathrm{M})(n=12)\end{array}$ & $0.5305 \pm \pm 0.0484$ & - \\
$\begin{array}{l}\text { Ouabain }(0.1 \mathrm{mM})+\text { furosemide } \\
(1 \mathrm{mM})(n=12)\end{array}$ & $0.1313 \pm 0.0063^{*}$ & - \\
$\begin{array}{l}\text { Ouabain }(0.1 \mathrm{mM}), \text { furosemide } \\
(1 \mathrm{mM}), \text { and inhibitin } \\
(0.1 \mu \mathrm{M})(n=12)\end{array}$ & & \\
& & \\
\end{tabular}

All data are shown as mean \pm 1 SD of 12 determinations. Inhibitin failed to have any significant effect (NS), whereas furosemide significantly decreased $(*, P$ $<0.001$ ) potassium influx into ouabain-treated cells. in the $\mathrm{Mg}^{2+}$ medium (i.e., sodium-free), lithium transport only occurs by pathways other than countertransport. The difference in lithium loss between the two solutions is therefore a measure of the maximum rate of lithium/sodium countertransport because external sodium ions stimulate lithium efflux. Fig. 1 shows the results of experiments in which the two solutions also contained $0.1 \mu \mathrm{M}$ inhibitin. $47 \%$ of the ouabain-insensitive lithium movement (difference between columns 1 and 3) can be attributed to lithium/sodium countertransport; this value is in agreement with previously published observations (11). Inhibitin produced significant inhibition $(46 \% ; P<0.02)$ of lithium efflux in the sodium medium (columns 1 and 2), reducing the value to that observed in the $\mathrm{Mg}^{2+}$ medium, but had no significant effect on the processes for lithium efflux which occur in the $\mathrm{Mg}^{2+}$ medium (columns 3 and 4). Addition of inhibitin, therefore, had the same effect as removal of sodium, i.e., complete inhibition of lithium/sodium countertransport. These results confirm that sodium/sodium exchange and lithium/sodium countertransport are one and the same process, which are capable of being blocked by inhibitin.

The interaction of inhibitin with other transport inhibitors. The concept that sodium/sodium exchange is a carrier-mediated transport process was tested in a series of experiments in which inhibitin, a specific inhibitor of this process, was used in combination with one or more of the other transport inhibitors. The

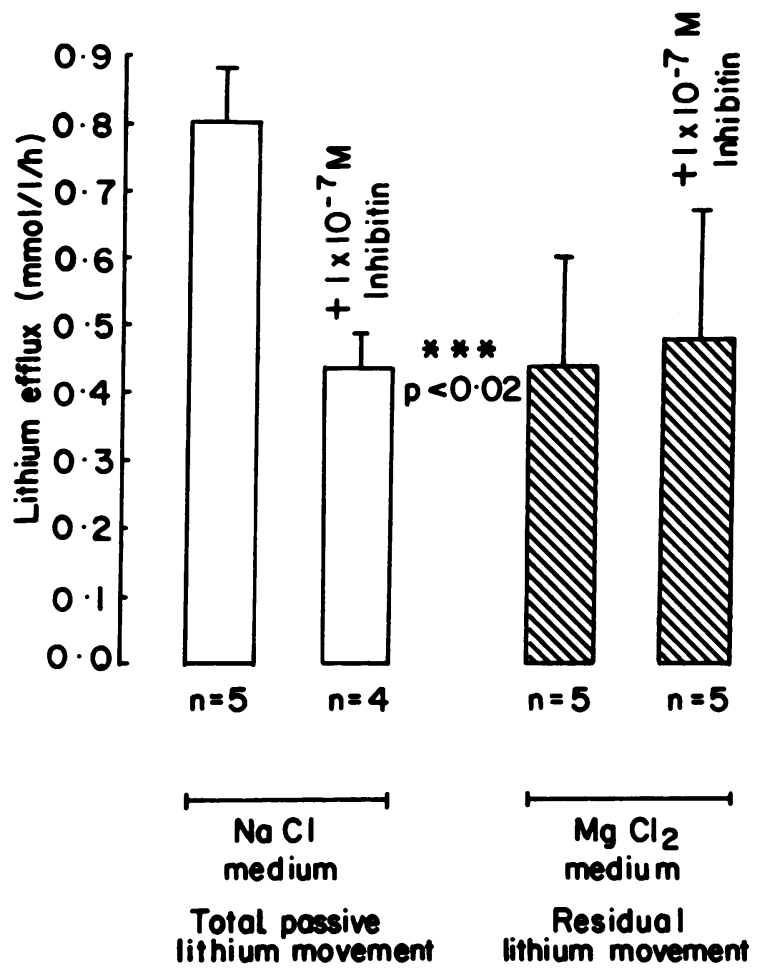

Figure 1. The effect of inhibitin $(0.1 \mu \mathrm{M})$ on lithium/sodium countertransport in ouabain $(0.1 \mathrm{mM})$-treated erythrocytes. Inhibitin produced significant $(P<0.02)$ inhibition of total passive lithium movement (in $\mathrm{NaCl}$ medium), but had no effect on the residual lithium movement (in $\mathrm{MgCl}_{2}$ medium). The lithium efflux in the presence of inhibitin was reduced to that observed in the absence of external sodium, i.e., complete inhibition of lithium/sodium countertransport. Data are shown as mean $\pm 1 \mathrm{SD}$ of a single donor and the number of determinations are indicated below each column. 
results of these experiments, as depicted in Fig. 2, clearly demonstrate that the inhibitin-sensitive portion of sodium transport (i.e., carrier-mediated sodium/sodium exchange diffusion) is distinct and does not overlap with the ouabain-sensitive (column $3, P<0.001$ ) or furosemide-sensitive (column $5, P<0.001$ ) sodium efflux components. The effect of inhibitin was also tested in the presence of amiloride. Under our experimental conditions, in which no $\mathrm{pH}$ gradient was established, amiloride did not produce inhibition of sodium efflux (data not shown). However, when inhibitin was added, a significant decrease in sodium efflux was again observed (column $7, P<0.005$ ). The inhibitin-sensitive component of sodium efflux always remained distinct and relatively constant $(0.43-0.50 \mathrm{mmol} /$ liter per $\mathrm{h})$; these values are in close agreement with the inhibitin-sensitive components of sodium efflux $(0.43 \mathrm{mmol} / \mathrm{liter}$ per $\mathrm{h})$ and sodium influx $(0.49$ $\mathrm{mmol} /$ liter per $\mathrm{h}$ ) shown in Table I. These experiments with other inhibitors suggest that the sodium/sodium exchange process is carrier-mediated and specifically inhibitable by inhibitin.

Effect of inhibitin on erythrocyte sodium/sodium exchange. Sodium efflux was measured in the presence of ouabain $(0.1$ $\mathrm{mM}$ ) and bumetanide $(0.1 \mathrm{mM})$ in Ringer's solution $(140 \mathrm{mM}$ sodium) and choline chloride solution ( $0 \mathrm{mM}$ sodium). Under these conditions, in Ringer's solution, sodium/sodium exchange will be maximal, with sodium "leak" also occurring due to the ground permeability of the membrane. In choline chloride solution, external sodium-stimulated sodium efflux (sodium ex-

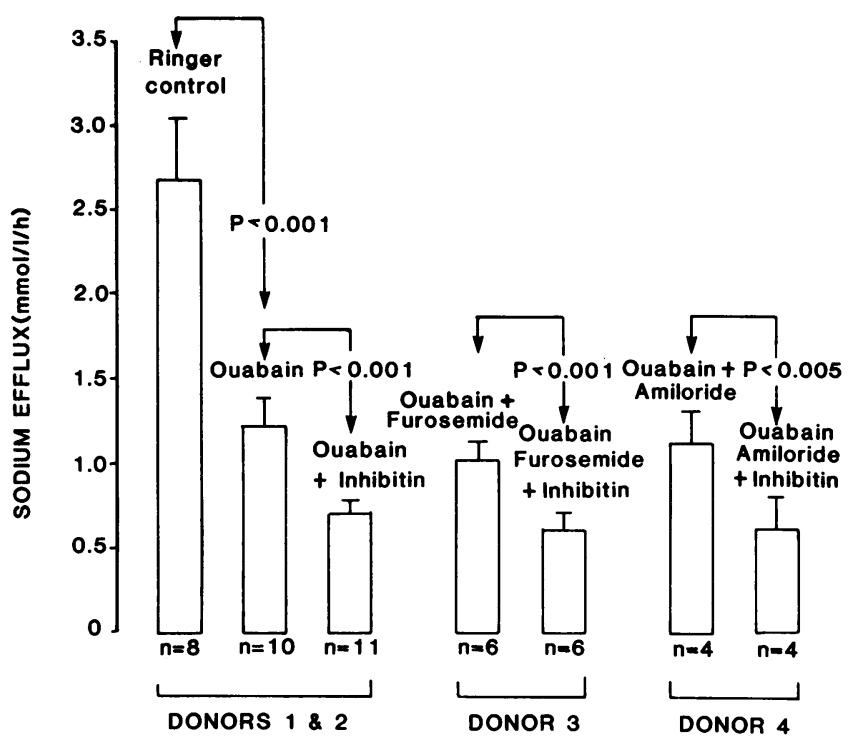

Figure 2. Histogram showing additional inhibition of sodium efflux rate constant caused by inhibitin in combination with other transport inhibitors, namely ouabain, which inhibits sodium-potassiumATPase; furosemide, which inhibits $\mathrm{Na}^{+}-\mathrm{K}^{+}-\mathrm{Cl}^{-}$cotransport; and amiloride, which blocks $\mathrm{Na}^{+} / \mathrm{H}^{+}$-exchange. Results are shown as mean \pm 1 SD from blood obtained from four separate donors, who were grouped as shown. The number of determinations is indicated under each column. The final concentrations of inhibitors was as follows: ouabain, $0.1 \mathrm{mM}$; inhibitin, $0.1 \mu \mathrm{M}$; furosemide, $1 \mathrm{mM}$, and amiloride, $1 \mathrm{mM}$. Ouabain alone decreased sodium efflux by $56 \%(P$ $<0.001$ ), giving an ouabain-sensitive fraction of $1.49 \mathrm{nmol} /$ liter per $h$. Inhibitin caused significant additional inhibition in the presence of ouabain $(41 \%, P<0.001)$; ouabain and furosemide $(42 \%, P<0.001)$; and ouabain and amiloride $(44 \%, P<0.005)$ with the inhibitin-sensitive component of sodium efflux amounting to $0.49,0.43$, and 0.50 $\mathrm{mmol} / \mathrm{liter}$ per $\mathrm{h}$, respectively. change) will not proceed, but sodium leak will. Therefore, the difference in sodium efflux in the two solutions represents a measure of sodium/sodium exchange by means of external sodium-stimulated sodium efflux. Inhibitin $(1 \mu \mathrm{M})$ was tested under these conditions and the results are summarized in Table III. The sodium/sodium exchange component was equivalent to $0.53 \mathrm{mmol} /$ liter per $\mathrm{h}$ (difference in sodium efflux between the 140 and $0 \mathrm{mM}$ external sodium solutions). In the presence of inhibitin, sodium efflux decreased $(73 \%, P<0.01)$ to that observed in the choline chloride medium, the inhibitin-sensitive component being $0.52 \mathrm{mmol} / \mathrm{liter}$ per $\mathrm{h}$. These results are in direct agreement with those from the lithium/sodium countertransport experiment (Fig. 1) where addition of inhibitin likewise reduced efflux to that observed in the absence of external sodium. In the choline chloride solution, inhibitin had no effect, indicating that it is specific for the sodium/sodium exchange carrier.

Inhibitin was also tested on sodium efflux in solutions that contained varying amounts of external sodium. These results are depicted in Fig. 3. Inhibitin continued to produce significant inhibition $(P<0.005)$ in the 100 and $50 \mathrm{mM}$ sodium solutions, but the effects were not significant at lower levels of external sodium as the efflux due to exchange diminished. These results suggest that inhibitin binds to the carrier that conducts sodium/ sodium exchange.

Effect of inhibitin on sodium-potassium-ATPase. Past studies have shown that intracellular sodium-stimulated, ouabain-insensitive, sodium efflux is not mediated through ATPase (7). However, the inhibitors used such as furosemide, ethacrynic acid, and analogues were not specific inhibitors of sodium/sodium exchange. The availability of a specific agent, inhibitin, once again raised the question whether there is any link between this transport system and sodium-potassium-ATPase. To address this question we studied the effect of inhibitin on sodium-potassium-ATPase from human erythrocytes and on ouabain binding to human red blood cells. Erythrocyte sodium-potassium-ATPase activity was $0.493 \pm 0.070(n=4) \mu \mathrm{mol}$ phosphate/ $\mathrm{mg}$ protein per $\mathrm{h}$. This accounted for $63 \%$ of total erythrocyte ATPase activity. In the presence of $0.1 \mu \mathrm{M}$ inhibitin, which had decreased ouabain-insensitive sodium transport, the value was $0.517 \pm 0.083(n=5)$. These results, together with those in Fig. 3 , show that inhibitin has no significant inhibitory effect on erythrocyte vesicle sodium-potassium-ATPase and that it does not displace $\left[{ }^{3} \mathrm{H}\right]$ ouabain from its binding site (Fig. 4). The inhibitory effect of inhibitin was also tested on canine kidney sodium-potassium-ATPase using an NADH-linked assay (23), in which ATP hydrolysis was enzymatically linked to NADH oxidation, and no inhibition was demonstrable (results not shown). These results show that the inhibitory effect of inhibitin on sodium/sodium exchange is not mediated through sodium-potassium-ATPase.

Effect of inhibitin on fibroblast sodium transport. While the erythrocyte is a very useful model for studying sodium transport pathways, it is atypical of most mammalian cells, as it is largely dependent on anaerobic metabolism. For this reason the effect of inhibitin has also been tested on normal human fibroblasts. All these experiments were performed in the presence of $1 \mathrm{mM}$ ouabain since the inhibitory effect of inhibitin on erythrocyte sodium movements is not mediated through sodium-potassiumATPase. The procedure used has been shown to be a reproducible and reliable method of measuring sodium transport in cultured fibroblasts (22). The ouabain-insensitive fibroblast sodium efflux was $36.7 \pm 1.6 \mu \mathrm{mol}$ sodium $/ \mathrm{g}$ protein per $\min (n=3)$, and this was significantly decreased $(P<0.001)$ to $30.8 \pm 0.9 \mu \mathrm{mol}$ so- 


\begin{tabular}{lcc}
\hline & $\begin{array}{l}\text { Ouabain and } \\
\text { bumetanide }\end{array}$ & $\begin{array}{c}\text { Ouabain, bumetanide, } \\
\text { and inhibitin }\end{array}$ \\
\hline significance
\end{tabular}

Results are shown as mean \pm 1 SD of triplicate measurements on erythrocytes obtained from a single donor. The internal sodium concentration was $7.1 \pm 0.3(n=3) \mathrm{mmol} / \mathrm{liter}$ erythrocytes. Inhibitin decreased the sodium efflux in the $140 \mathrm{mM}$ external sodium solution to that observed in the choline chloride medium.

dium/g protein per min in the presence of $0.1 \mu \mathrm{M}$ inhibitin. The inhibitin-sensitive component of fibroblast sodium efflux amounted to $5.9 \pm 0.9 \mu \mathrm{mol}$ sodium $/ \mathrm{g}$ protein per min. These data show that the erythrocyte is not unique in having an inhibitin-sensitive component of sodium transport.

\section{Discussion}

The dual purpose of this study was to establish the precise locus of action of inhibitin on erythrocyte sodium movements and,

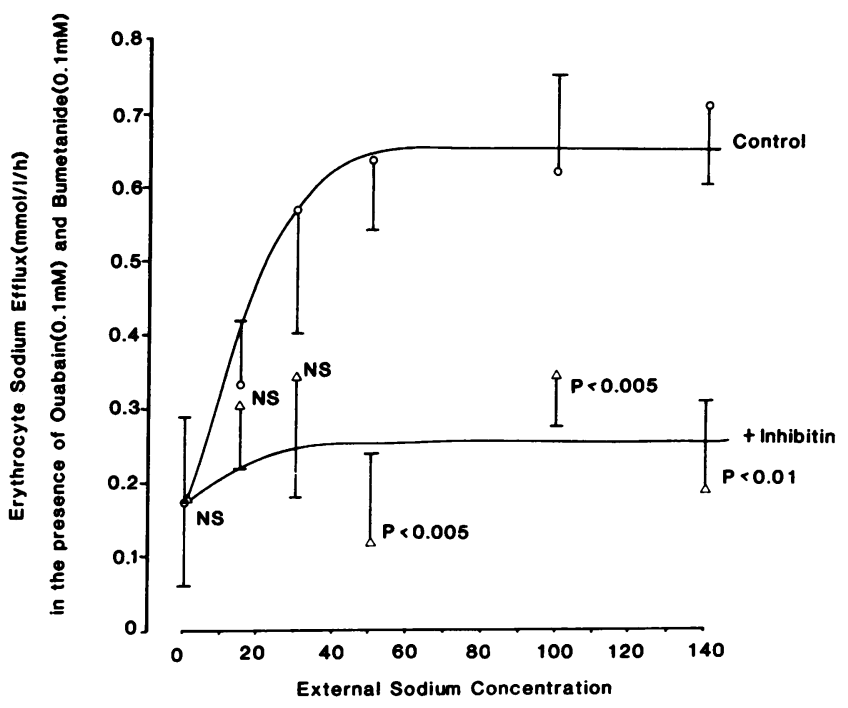

Figure 3. The effect of inhibitin $(1 \mu \mathrm{M})$ on erythrocyte sodium efflux in the presence of ouabain $(0.1 \mathrm{mM})$ and bumetanide $(0.1 \mathrm{mM})$ in solutions containing different concentrations of sodium. External sodium up to $50 \mathrm{mM}$ stimulated sodium efflux to a maximum (o); above this concentration the system was saturated and efflux remained constant. In the presence of inhibitin $(\Delta)$, the amount of efflux through this pathway was decreased. As the external sodium increased, so the amount of inhibition became greater and more easily detectable. All points are shown as mean \pm 1 SD of triplicate measurements, which were made on blood donated by a single subject. using inhibitin with other inhibitors, to gain an insight into the processes of sodium transport in the red blood cell. The data presented provide strong evidence that inhibitin exerts its inhibitory effect on erythrocyte sodium transport by blocking a distinct carrier-mediated sodium/sodium exchange process that is not inhibited by ouabain, furosemide, or bumetanide. Past experience with these inhibitors has suggested that stringent criteria must be applied before a substance is accepted as being a specific inhibitor of sodium/sodium exchange, since diuretics and phloretin, previously considered to be sodium/sodium exchange inhibitors, have not fulfilled that promise. We believe

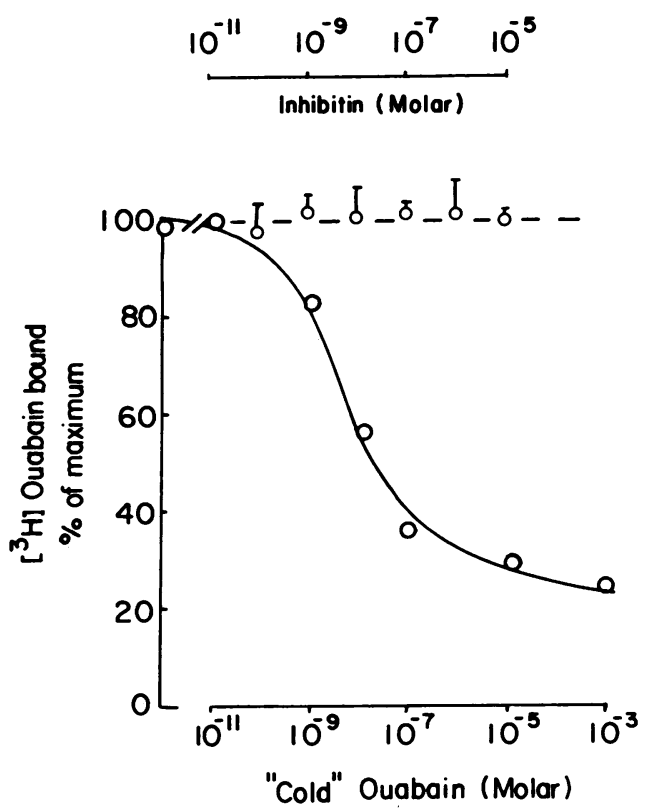

Figure 4. The effect of unlabeled ("cold") ouabain (- - ) and inhibitin (-- $\mathrm{O}--)$ on ${ }^{3}[\mathrm{H}]$ ouabain binding to intact human erythrocytes. The displacement curve with cold ouabain was obtained from triplicate samples with an intra-assay variability of $<5 \%$. Inhibitin was tested in triplicate on three occasions, and the results, shown as mean $\pm \mathrm{SD}$, show that inhibitin does not displace the tritium label. 
that a specific inhibitor of sodium/sodium exchange must fulfill at least six requirements: $(a)$ show equal inhibition of sodium influx and efflux; $(b)$ the effect should decrease when external sodium is lowered; $(c)$ have no effect on net sodium transport; $(d)$ have no effect on potassium fluxes; $(e)$ show no effect on sodium-potassium-ATPase; and $(f)$ it should show inhibition in addition to that achieved with the inhibitors of other processes. The results presented in this paper show that the inhibitory characteristics of inhibitin meet all six requirements. Inhibitin reduces both sodium efflux and influx by equivalent amounts and does not alter net transport of sodium (Table I), it has no significant effect on potassium influx (Table II), inhibition is not seen when external sodium is removed (Table III and Fig. 3), it has no effect on sodium-potassium-ATPase, and its inhibitory effect is distinct and unaffected when combined with other inhibitors (Fig. 2). The last characteristic suggests that no other inhibitor affects the transport system that is inhibited by inhibitin.

Although furosemide, and later phloretin, have both been credited to possess inhibitory activity on sodium/sodium exchange, neither had been shown to have a specific inhibitable component that did not overlap with, nor was influenced by, the effect of other inhibitors. This was partly resolved by the studies of Wiley and Cooper (8), who demonstrated that furosemide inhibited a specific sodium/potassium cotransport process which was distinct from other pathways. Phloretin has been shown to inhibit sodium/lithium countertransport (11) and partially inhibit sodium/sodium exchange (24). Our studies have shown that phloretin, in increasing concentrations, interferes with other transport pathways (unpublished data), which suggests than its effects are nonspecific and are probably achieved through a toxic effect on the membrane. Shefcyk et al. (13) have shown that phloretin binds to membrane lipids, adjacent to carrier proteins, thereby affecting transport processes. Our recent unpublished studies have shown that its actions overlap with those of others and that it inhibits active transport in the absence of ouabain. However, it does not displace ${ }^{3}[\mathrm{H}]$ ouabain from its binding site, which suggests that its inhibitory effects of various transport pathways are achieved through its nonspecific interference with lipid and protein components of the membrane.

Sodium/sodium and sodium/lithium exchanges are known to operate through the same carrier $(11,12)$. The present study shows that a specific inhibitor of sodium/sodium exchange also inhibits sodium/lithium countertransport. This suggests that both processes are indeed conducted through the same pathway. In this regard, the availability of inhibitin, as a specific inhibitor of sodium/sodium exchange, should make an important contribution in defining differing transport characteristics, e.g., the relationship between sodium/sodium and sodium/hydrogen exchange systems, and also in determining the sodium transport pathways which exist in various cell types.

\section{Acknowledgments}

We thank Dr. M. Wagstaff, Department of Hematology, University of Wales College of Medicine (Cardiff) for the leukemic promyelocyte (HL60) cell line; Dr. Don Bradley, Department of Medicine, for amino acid analyses; and Mrs. Annette Price for typing this manuscript.

This study was supported by the Wellcome Trust.

\section{References}

1. Skou, J. C. 1965. Enzymatic basis for active transport of $\mathrm{Na}^{+}$and $\mathrm{K}^{+}$across cell membrane. Physiol. Rev. 45:596-617.

2. Glynn, I. M. 1968. Membrane adenosine triphosphate and cation transport. Br. Med. Bull. 24:165-169.
3. Hoffman, J. F., and F. M. Kregenow. 1966. The characteristics of new energy dependent cation transport processes in red blood cells. Ann. NY Acad. Sci. 137(2):566-576.

4. Sachs, J. R. 1971. Ouabain-insensitive sodium movements in the human red blood cell. J. Gen. Physiol. 57:259-282.

5. Lubowitz, H., and R. Whittam. 1969. Ion movements in human red cells independent of the sodium pump. J. Physiol. (Lond.). 202:111131.

6. Dunn, M. J. 1970. The effects of transport inhibitors on sodium outflux and influx in red blood cells: evidence for exchange diffusion. $J$. Clin. Invest. 49:1804-1814.

7. Dunn, M. J. 1973. Ouabain-uninhibited sodium transport in human erythrocytes: evidence against a second pump. J. Clin. Invest. 52 658-670.

8. Wiley, J. S., and R. A. Cooper. 1974. A furosemide-sensitive cotransport of sodium plus potassium in the human red cell. J. Clin. Invest. 53:745-755.

9. Canessa, M., I. Bize, N. Adragna, and D. Tosteson. 1982. Cotransport of lithium and potassium in human red cells. J. Gen. Physiol. 80: 149-168.

10. Duhm, J., and B. O. Gobel. 1984. Role of the furosemide-sensitive $\mathrm{Na}^{+} / \mathrm{K}^{+}$transport system in determining the steady-state $\mathrm{Na}^{+}$and $\mathrm{K}^{+}$ content and volume of human erythrocytes in vitro and in vivo. J. Membr. Biol. 77:243-254.

11. Pandey, G. N., B. Sarkadi, M. Hass, R. B. Gunn, J. M. Davies, and D. C. Tosteson. 1978. Lithium transport pathways in human red blood cells. J. Gen. Physiol. 72:233-247.

12. Sarkadi, B., J. K. Allifimoff, R. B. Gunn, and D. C. Tosteson. 1978. Kinetics and stoichiometry of Na-dependent $\mathrm{Li}$ transport in human red blood cells. J. Gen. Physiol. 72:249-265.

13. Shefcyk, J., T. F. P. Molski, M. Volpi, P. H. Naccache, and R. I. Sha'afi. 1983. Phloretin is a potent inhibitor of rabbit neutrophil activation by chemotatic factors. Biochim. Biophys. Acta. 728:97-102.

14. Morgan, K., and M. A. Mir. 1984. Isolation of a sodium transport inhibitory factor, inhibitin, from cultured leukemic promyelocytes. $J$. Clin. Invest. 74:1132-1142.

15. Mir, M. A., and H. Bobinski. 1975. Altered membrane sodium transport and the presence of a plasma ouabain-like inhibitory factor in acute myeloid leukaemia. Clin. Sci. Mol. Med. 48:213-218.

16. Sachs, J. R., and L. G. Welt. 1967. The concentration dependence of active potassium transport in the human red blood cell. J. Clin. Invest. 46:65-67.

17. Canessa, M., M. Adragna, H. S. Solomon, T. M. Connoly, and D. C. Tosteson. 1980. Increased sodium-lithium counter-transport in red cells of patients with essential hypertension. N. Engl. J. Med. 302: 772-776.

18. Charalambous, B. M., and M. A. Mir. 1982. An improved procedure for the preparation and measurement of $\left(\mathrm{Na}^{+}+\mathrm{K}^{+}\right)$-ATPase in human erythrocytes. Biochim. Biophys. Acta. 691:71-82.

19. Bradford, M. M. 1976. A rapid and sensitive method for the quantitation of microgram quantities of protein utilizing the principle of protein-dye binding. Anal. Biochem. 72:248-254.

20. Lin, T., and M. F. Morales. 1977. Application of a one-step procedure for measuring inorganic phosphate in the presence of proteins: the actinomysin ATPase system. Anal. Biochem. 77:10-17.

21. Erdmann, E. 1982. Binding studies with $\left[{ }^{3} \mathrm{H}\right]$ ouabain to red cell membranes. In Red Cell Membranes: A Methodological Approach. J. C. Ellory and J. D. Young, editors. Academic Press, London. 251262.

22. Spurlock, G., K. Morgan, and M. A. Mir. 1986. A reproducible procedure for measuring sodium transport in cultured human fibroblasts from normal and obese donors. Clin. Chim. Acta. In press.

23. Scharschmidt, B. F., E. B. Keefe, N. M. Blakenship, and R. K. Ockner. 1979. Validation of a recording spectrophotometric method for measurement of membrane-associated $\mathrm{Mg}$ - and $\mathrm{Na}, \mathrm{K}-\mathrm{ATPase}$ activity. J. Lab. Clin. Med. 93:790-799.

24. Pandey, G. N., D. G. Ostrow, M. Haas, E. Dorus, R. C. Casper, J. M. Davies, and D. C. Tosteson. 1977. Abnormal lithium and sodium transport in erythrocytes of a manic patient and some members of his family. Proc. Natl. Acad. Sci. USA. 74:3607-3611. 